\title{
A Novel Design of Microstrip Arrays for Relay-Based Wireless Network
}

\author{
Ioannis Petropoulos, ${ }^{1,2}$ Konstantinos Voudouris, ${ }^{1}$ Raed A. Abd-Alhameed, ${ }^{2}$ \\ Steve M. R. Jones, ${ }^{2}$ and Nikos Athanasopoulos ${ }^{1}$ \\ ${ }^{1}$ Department of Electronics, Technological Educational Institute of Athens (TEI), Ag. Spyridonos, 12210 Athens, Greece
${ }^{2}$ School of Engineering, Design and Technology, University of Bradford, Richmond Road, Bradford BD7 1DP, UK
}

Correspondence should be addressed to Ioannis Petropoulos, ipetro@teiath.gr

Received 19 April 2011; Revised 27 June 2011; Accepted 12 July 2011

Academic Editor: Hoi Shun Lui

Copyright (C) 2011 Ioannis Petropoulos et al. This is an open access article distributed under the Creative Commons Attribution License, which permits unrestricted use, distribution, and reproduction in any medium, provided the original work is properly cited.

\begin{abstract}
A relay station (RS) is a smart transceiver used under a $4 \mathrm{G}$ wireless network in order to extend network's coverage and capacity. It uses an antenna system that includes an antenna for connecting the relay with the end users (access link) and the RS with the base station (backhaul link). In this paper, a $7.9 \mathrm{dBi}$ access and $11.4 \mathrm{dBi}$ backhaul antennas are presented for the frequency range of 3.3 to $3.8 \mathrm{GHz}$. The antennas are simulated and fabricated, and relevant measured results in terms of return loss and radiation pattern are presented and analyzed. Considering that the planes of those two antennas are positioned in an angle $\omega$ (omega), two antenna configuration geometries are tested in terms of coupling. The experimental results of $S_{21}$ for several values of the angle $\omega$ show that the interaction between the radiating elements is dependent on their relative position. Simulated and experimental results are in good agreement, showing coupling typically less than $-40 \mathrm{~dB}$. A comparison in terms of coupling between the proposed antennas and commercial ones proves that the suggested antennas provide $10 \mathrm{~dB}$ lower coupling.
\end{abstract}

\section{Introduction}

Relay stations (RSs) are network element devices, designed to fill holes in the base station (BS) coverage. They receive, enhance, and then retransmit the signal after digital processing [1]. The antenna system is critical to the operation of the relay station (RS). It aims to connect RS with BS realizing the backhaul connection and RS with user subscribers, realizing the access link. Relays can be used in many wireless networks. The present study refers to a WiMAX wireless network in the range of 3.3 to $3.8 \mathrm{GHz}$.

Figure 1 summarizes the operation of an antenna system showing that relay station can be an intermediate link between base station and end user. Such a topology can ensure high quality of data transmission using an antenna system that can efficiently receive and transmit information.

Many antennas have been proposed for use in the WiMAX frequency range, such as $\mathrm{U}$ and $\mathrm{C}$ slot antennas $[2,3]$, $\mathrm{U}$ shaped patches [4], and PIFA [5]. Another important issue associated with the antenna is coupling. Coupling is a phe- nomenon that expresses the level of interaction between radiation elements. It is necessary to maintain coupling as low as possible to prevent distortion of the transmitted signal. Several studies have been carried out, investigating methods to predict and evaluate mutual coupling [6-9]. Also special attention has been given to mutual coupling reduction, by placing resonators between radiating elements [10] or by using planar EBG structures [11, 12].

In this paper, two simple, low-cost planar antennas, based on microstrip technology, one for the access link and one for backhaul link, are designed and presented. These antennas are compared to commercial ones, and their features are outlined. The two proposed antennas are positioned together and are examined in terms of coupling. Experimental and simulated results of $S_{21}$ are presented and compared. A clear relation between coupling and the angle between the access and backhaul antenna is found. Finally, a coupling comparison between the suggested and commercial antennas is performed, and corresponded results are depicted. 


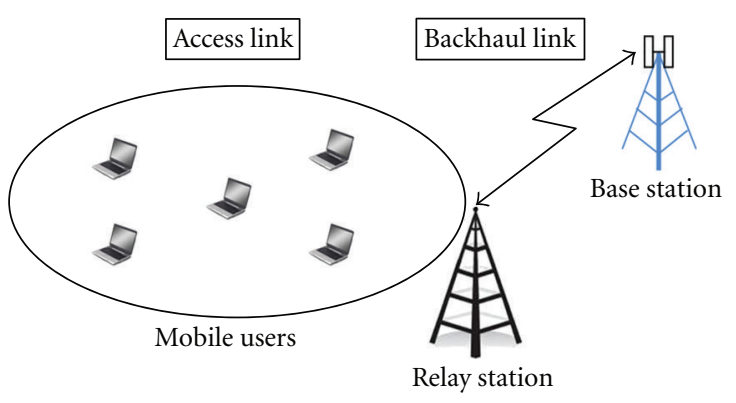

FIgURE 1: Relay station operation.

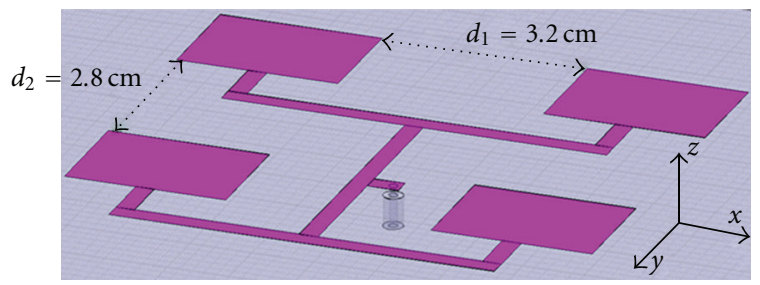

(a)

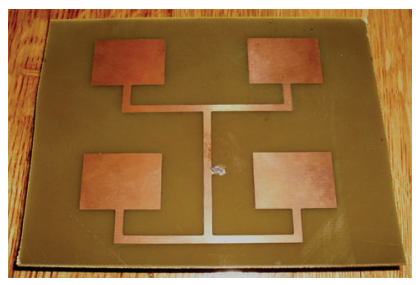

(b)

Figure 2: Antenna geometry and measurements; (a) antenna model, (b) antenna prototype.

\section{Access Antenna}

An access antenna was simulated and fabricated, and the relevant results are depicted below. Four patches (radiating elements) fed by microstrip lines are placed on FR4 substrate $\left(\varepsilon_{r}=4.4, h=1.6 \mathrm{~mm}\right)$. The excitation is realized by a coaxial cable which is connected to microstrip line. The simulated antenna is depicted in Figure 2(a), while the fabricated one can be seen in Figure 2(b). Access antenna's dimensions are $12.5 \mathrm{~cm} \times 10 \mathrm{~cm}$. Simulations have been performed using Ansoft HFSS v.12. Measurements of return loss $\left(S_{11}\right)$ and radiation pattern have been taken in an anechoic chamber.

The $S_{11}$ parameter as a function of frequency is depicted. Figure 3 depicts the simulated and measured curves of $S_{11}$ as a function of frequency, for the access antenna. Curves are in good agreement, showing resonance at $3.5 \mathrm{GHz}$.

For the experimental estimation of $S_{11}$, a Vector Network Analyzer was used (Anritsu VNA MS2036A). Before measurements, calibration was performed in order to take into consideration the cable losses and increase the level of experiment accuracy. The excitation of access and backhaul antennas is realized by a coaxial cable which feeds the microstrip line. In the connecting point between cable and microstrip line, losses are introduced that reduce the amount of

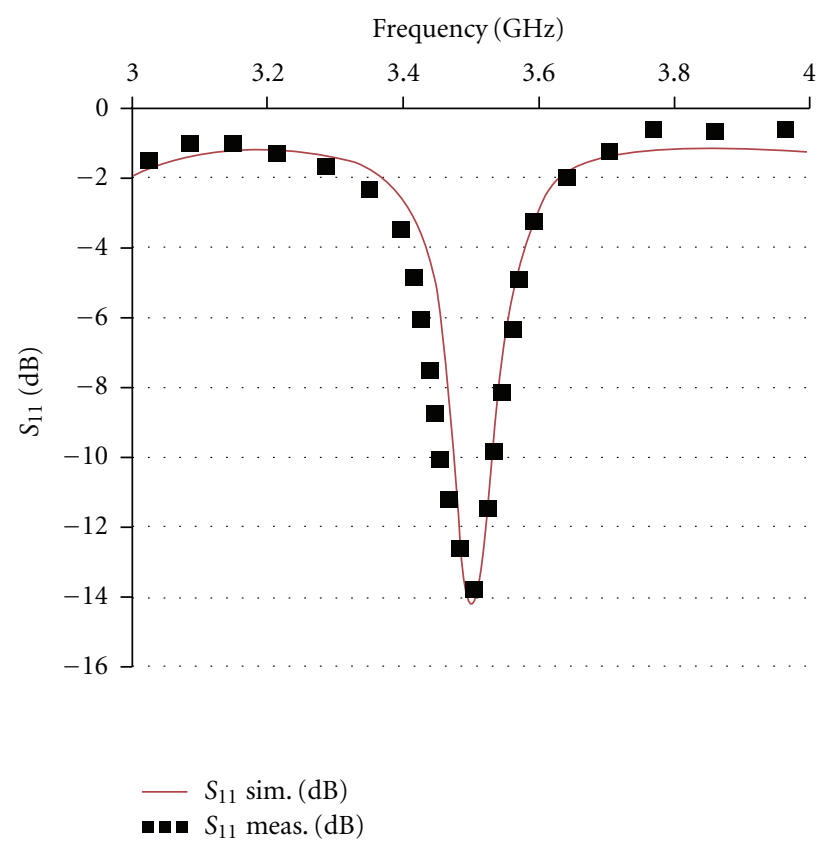

FIgURE 3: $S_{11}$ parameter for simulated and fabricated antenna.

power that enters the antenna. That is why this antenna presents narrow bandwidth [13].

Access antenna presents $S_{11}=-14.23 \mathrm{~dB}$ for $3.5 \mathrm{GHz}$. The impedance bandwidth of the antenna is estimated to be $31.8 \mathrm{MHz}\left(S_{11}<-10 \mathrm{~dB}[14]\right)$. The radiation pattern of the simulated and fabricated antenna is illustrated in Figure 4(a) for yz plane at $3.5 \mathrm{GHz}$. Half-power beamwidth (HPBW) is $35.96^{\circ}$. The antenna presents gain $G=7.94 \mathrm{dBi}$ in the direction of maximum emission. Let us mention here that FR4 substrate has an increased loss tangent $(\tan \delta=0.02)$ which means low-quality factor and thus increased dielectric losses. That is why the antenna gain appeared to be less than what is expected but high enough to support the access link.

The radiation pattern in $\mathrm{xz}$ plane is depicted in Figure 4(b), presenting $\mathrm{HPBW}=51.07^{\circ}$.

Figures 4(a) and 4(b) also depict the simulated cross polarization level of the access antenna. Cross polarization expresses the amount of power-emitted orthogonal to the desired direction, and it has to be as low as possible. Surface waves are dependent of the substrate and give rise to cross polarization. For minimizing these waves, materials with low dielectric losses could be chosen.

\section{Backhaul Antenna}

An antenna array intended to be used for connecting the relay with the base station is presented in this section. The simulated and constructed antenna can be seen in Figures 5(a) and 5(b), respectively. Backhaul antenna's dimensions are $25.5 \mathrm{~cm} \times 21.5 \mathrm{~cm}$.

The $S_{11}$ parameter for the simulated and fabricated antenna is shown below (Figure 6) where a slight difference is attributed to the imprecise process of construction. 

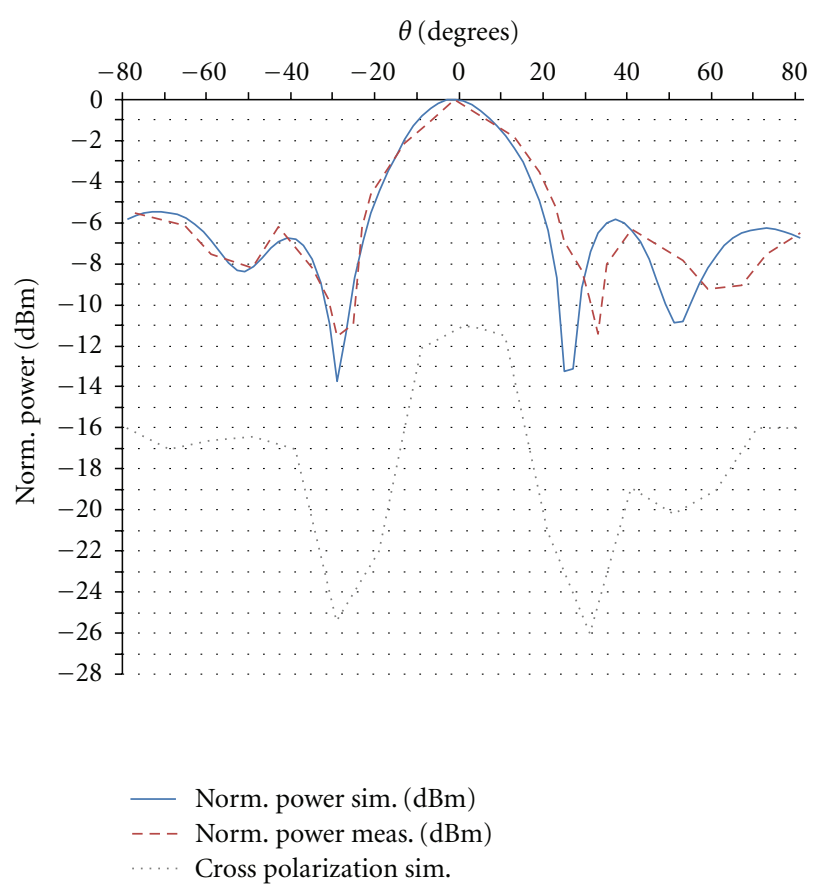

(a)

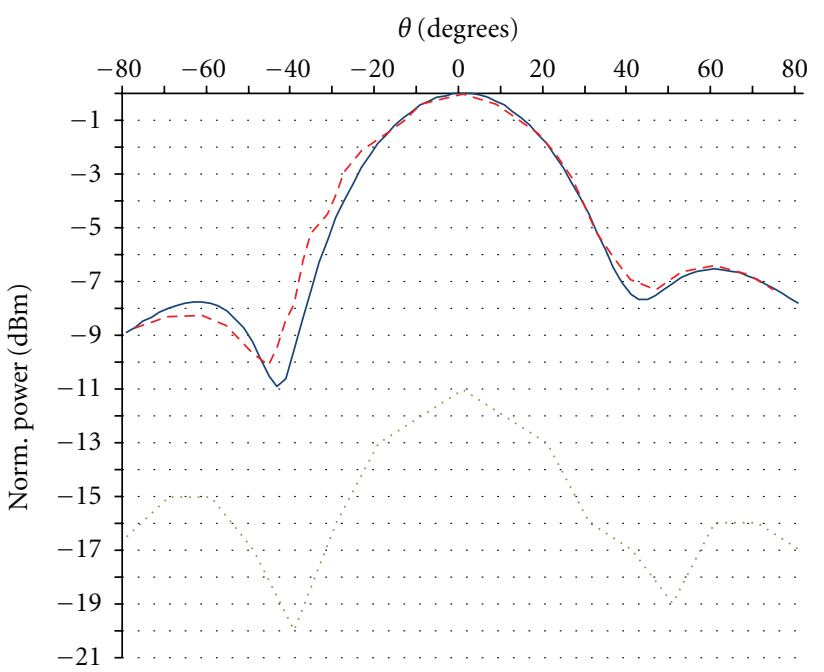

$\begin{array}{ll}- & \text { Norm. power sim. }(\mathrm{dBm}) \\ -\ldots- & \text { Norm. power meas. }(\mathrm{dBm}) \\ \ldots . . . & \text { Cross polarization sim. }\end{array}$

(b)

FIgURE 4: (a) Radiation pattern of access antenna in yz plane for $3.5 \mathrm{GHz}$. (b) Radiation pattern of access antenna in xz plane for $3.5 \mathrm{GHz}$.

TABLE 1: Access and backhaul antenna features.

\begin{tabular}{|c|c|c|c|c|c|}
\hline & $S_{11}(\mathrm{~dB})$ for $3.5 \mathrm{GHz}$ & Gain $(\mathrm{dBi})$ & $\begin{array}{l}\text { HPBW (degrees) xz } \\
\text { plane }\end{array}$ & $\begin{array}{l}\text { HPBW (degrees) yz } \\
\text { plane }\end{array}$ & Bandwidth (MHz) \\
\hline Access antenna & -14.23 & 7.9 & 51.07 & 35.96 & 31.8 \\
\hline $\begin{array}{l}\text { Commercial access } \\
\text { antenna } \\
(1 \mathrm{SKF}-333808 \mathrm{~W})\end{array}$ & -15.08 & 8 & 68 & - & 500 \\
\hline Backhaul antenna & -20.46 & 11.4 & 25.45 & 18.20 & 83.9 \\
\hline $\begin{array}{l}\text { Commercial } \\
\text { backhaul antenna } \\
\text { (TSWL315177) }\end{array}$ & -18.48 & 18 & 17 & - & 400 \\
\hline
\end{tabular}

Backhaul antenna presents $S_{11}=-20.46 \mathrm{~dB}$ at $3.5 \mathrm{GHz}$, and impedance bandwidth is equal to $83.9 \mathrm{MHz}$. A second resonance frequency appeared at $3.9 \mathrm{GHz}$ where $S_{11}=$ $-14.17 \mathrm{~dB}$. The gain of the backhaul antenna has been found to be $11.4 \mathrm{dBi}$ for $3.5 \mathrm{GHz}$. Gain could be greater if a substrate of lower dielectric losses was used.

The radiation pattern is presented in Figure 7(a) where a narrow beam is noticed due to the increase in the number of radiation elements compared to the case of the access antenna. HPBW has been measured $18.2^{\circ}$.

The radiation pattern in $\mathrm{xz}$ plane is presented in Figure $7(\mathrm{~b})$. In this case, $\mathrm{HPBW}=25.45^{\circ}$.

Figures $7(\mathrm{a})$ and $7(\mathrm{~b})$ also represent the cross polarization level which appeared to be increased due to the FR4 substrate.

Measured access and backhaul antenna characteristics are denoted in Table 1.
Gain and bandwidth are increased in the case of the backhaul antenna due to the larger number of radiation elements (16 elements) compared to the access antenna (4 elements). Also half-power beamwidth (HPBW) is decreased in the backhaul antenna. In addition, a comparison is performed between the proposed antennas and relevant commercial ones. Regarding access antenna, model 1SKF-333808W is a panel antenna presenting $\mathrm{HPBW}=68^{\circ}$, gain $8 \mathrm{dBi}$, and bandwidth $500 \mathrm{MHz}$. The proposed access antenna gives similar gain but less HPBW and bandwidth due to FR4 substrate. Bandwidth could be enlarged by using a substrate of lower loss tangent such as Rogers RO $3006\left(\varepsilon_{r}=6.15, \tan \delta=\right.$ $0.0025)$ or Rogers RT Duroid $5880\left(\varepsilon_{r}=2.2, \tan \delta=0.0009\right)$. Wider bandwidth could also occur using stacked geometry including two or more substrates separated by air gaps. FR4 substrate was chosen because of its low cost and ease of fabrication. Regarding backhaul antenna, the commercial one 


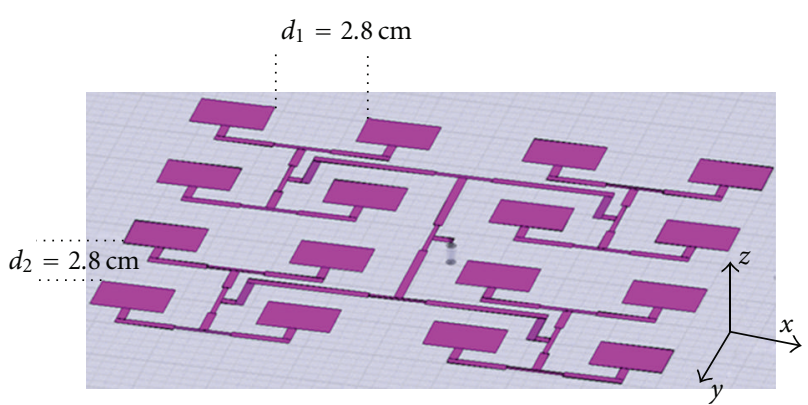

(a)

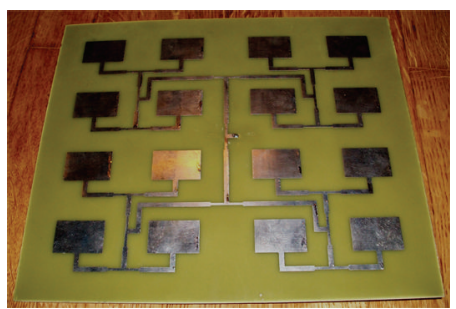

(b)

Figure 5: Backhaul antenna geometry and measurements. (a) Backhaul antenna model, (b) backhaul antenna prototype.

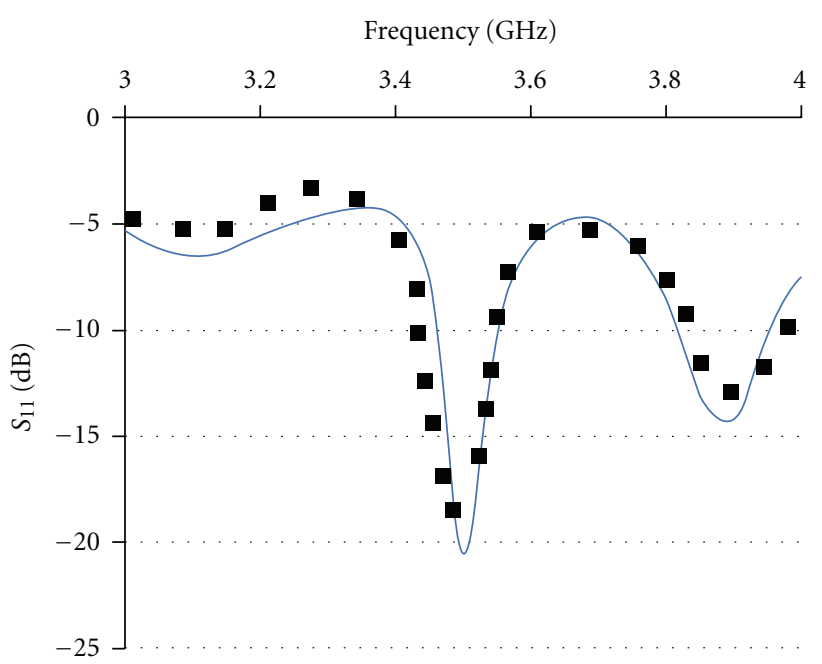

- $S_{11} \operatorname{sim} .(\mathrm{dB})$

-1. $S_{11}$ meas. $(\mathrm{dB})$

FIGURE 6: $S_{11}$ parameter for backhaul antenna.

presents enhanced bandwidth and gain. The proposed backhaul antenna uses low-cost FR4 substrate which has high loss tangent that leads to limited gain, bandwidth, and high sidelobes. The design of access and backhaul antenna has been made maintaining low cost of fabrication and low complexity level. Both antennas can be improved in terms of gain and bandwidth by using stacked geometries and dielectrics of low losses.

Both access and backhaul antennas operate at the same frequency and provide a limited radio bandwidth. This is not

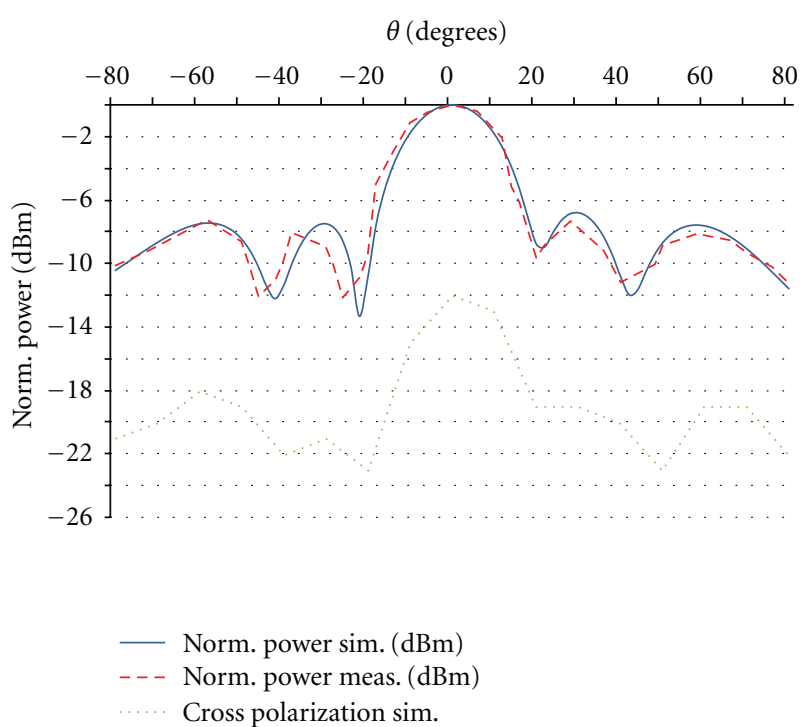

(a)

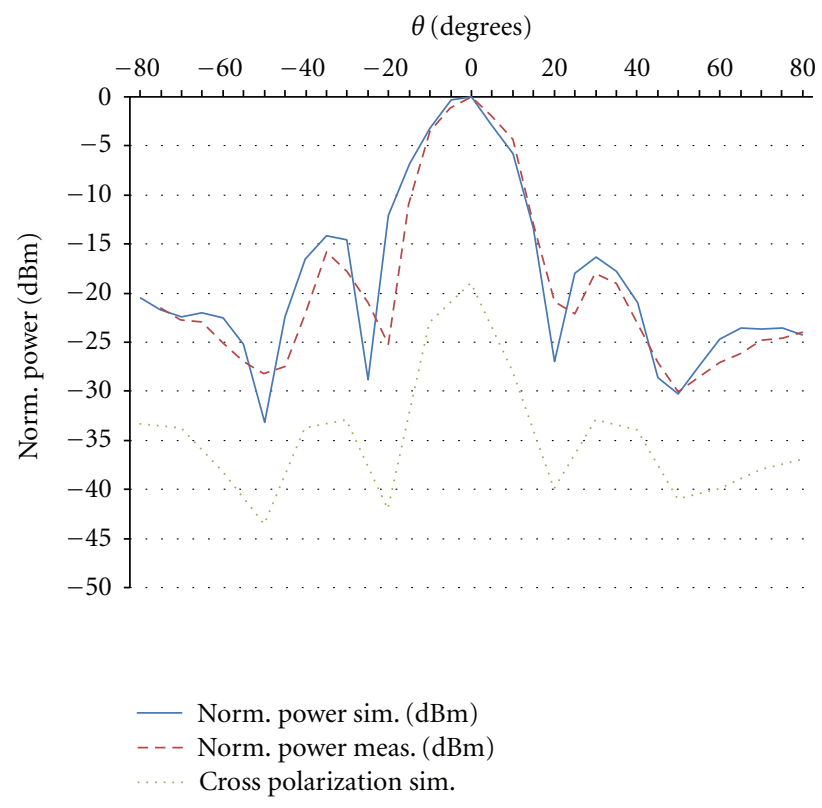

(b)

FIGURE 7: (a) Radiation pattern of backhaul antenna in yz plane for 3.5 GHz. (b) Radiation pattern of backhaul antenna in $x z$ plane for $3.5 \mathrm{GHz}$.

a drawback if we take into consideration that the relay station provides high spectral efficiency. Since both proposed antennas have the same resonant frequency and the relay station performs in the simultaneously transmit-receive (STR) mode, it is necessary to examine the coupling phenomenon between the antennas.

\section{Coupling Effects Study}

Two cases of configuration between the proposed antennas are examined. These configurations are shown in the figures that follow. Coupling between the two antennas in terms of $S_{21}$ is measured using Anritsu VNA MS2036A, and results are 


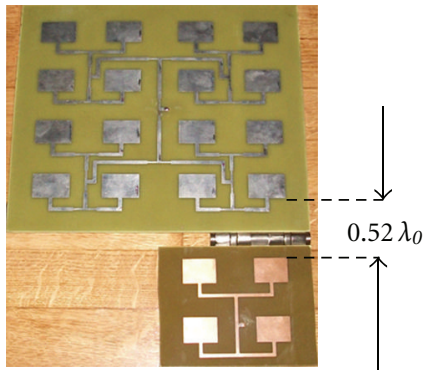

(a)

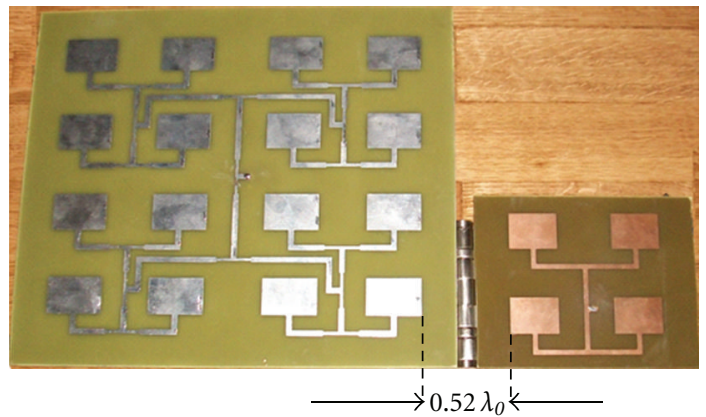

(b)

Figure 8: Antenna arrangements under test; (a) configuration 1, (b) configuration 2 .

depicted. The tested setup is depicted in Figure 8 where two similar configurations are shown.

Coupling measurements have been taken in anechoic chamber to achieve precision and validity of results. Figures 9(a) and 9(b) show the experimental setup. The distance between two adjacent radiation elements of access and backhaul antennas is $0.52 \lambda_{o}$. This distance is adequate for low mutual coupling [15] and maintaining the total size of the antenna system as small as possible.

Study of configurations 1 and 2 due to the relative position of antennas can be considered as coupling investigation in E-plane and H-plane, respectively.

4.1. Configuration 1. In the first case (configuration 1), the two antennas are put in such a way so that the angle between them is $\omega=180^{\circ}$ and then $\omega$ increases with a step of $10^{\circ}$ and finally reaches $270^{\circ}$. The scheme that specifies the proposed setup can be seen in Figure 10.

Together with the experimental measurements, simulations of $S_{21}$ as a function of the angle $\omega$ have been carried out. Simulation and measurement of $S_{21}$ for the case of $\omega=180^{\circ}$ is depicted in Figure 11(b).

Figure 11(b) shows that simulation and experimental curve of $S_{21}$ is located below $-40 \mathrm{~dB}$ for the frequency range of 3.4 to $3.6 \mathrm{GHz}$.

For $\omega=190^{\circ}$, the experimental setup is depicted in Figure 12(a) and the corresponded results in Figure 12(b).

For $\omega=200^{\circ}$, the experimental setup is depicted in Figure 13(a) and the corresponded results in Figure 13(b).

The experiment continues for $\omega=210^{\circ}$ till $270^{\circ}$ with a step of $10^{\circ}$. Coupling can change the operation frequency of

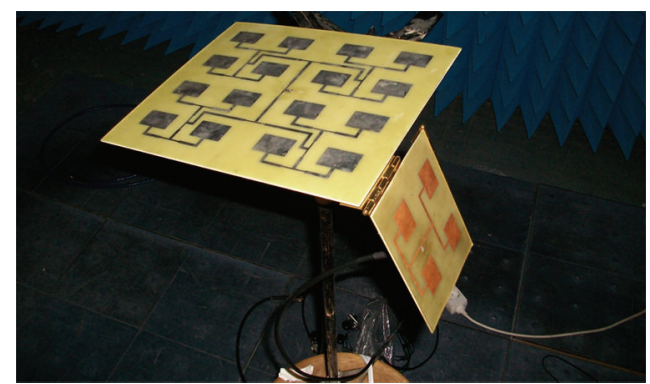

(a)

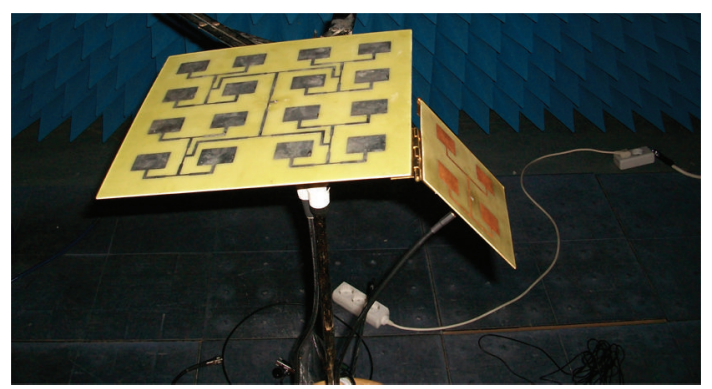

(b)

Figure 9: Access and backhaul antenna setup during coupling measurements.

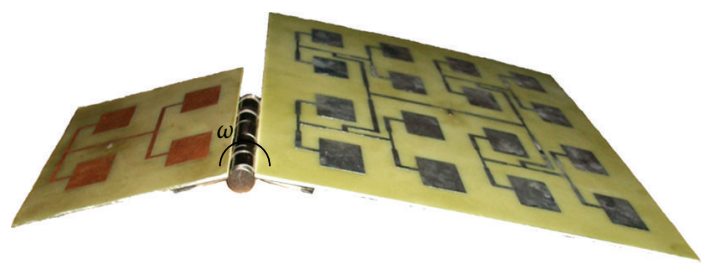

FIGURE 10: The investigated setup.

an antenna and distort the radiation pattern; that is why it is necessary to maintain coupling at a low level. Coupling effect is mainly caused by space waves that end up from one antenna to another (Figure 14). It is also dependent on surface waves that travel through dielectric [15]. From the analysis performed for configuration 1, it is derived that increasing the angle $\omega$ seems to reduce the density of field lines that end up from one antenna to the other thus reducing coupling effect.

4.2. Configuration 2. In this case, the access and backhaul antennas are positioned as shown in Figure 15.

Together with the experimental measurements, simulations of $S_{21}$ against angle $\omega$ for configuration 2 have been performed. The case of $\omega=180^{\circ}$ is depicted in Figure 16(b).

Figure 16(b) represents the simulation and experimental curve for $S_{21}$. Coupling is at an acceptable level $(<-40 \mathrm{~dB})$ for the frequency range 3.4 to $3.6 \mathrm{GHz}$.

For $\omega=190^{\circ}$, the corresponded results can be seen in Figure 17(b).

For $\omega=200^{\circ}$, the experimental setup is depicted in Figure 18(a) and the corresponded results in Figure 18(b). 


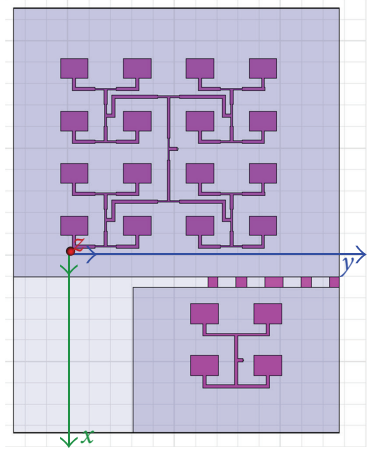

(a)

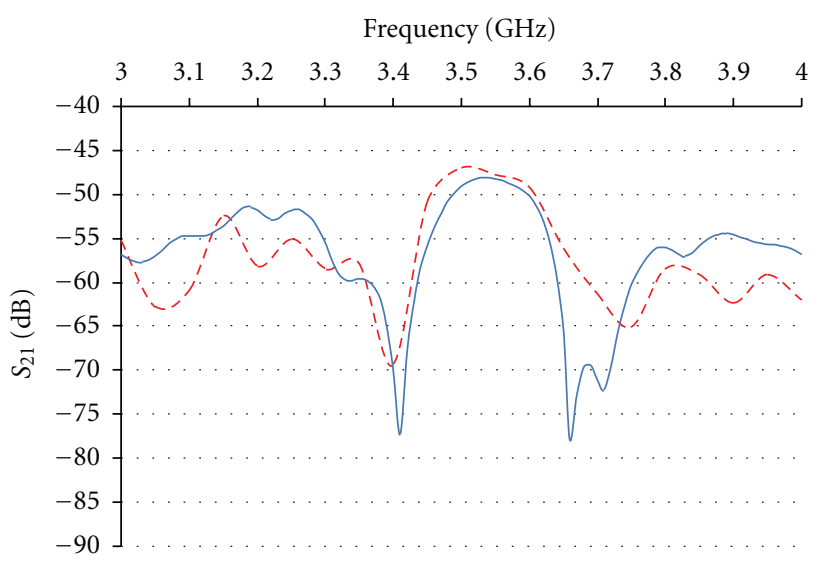

$-S_{21} \operatorname{sim} .(\mathrm{dB})$

$--S_{21}$ meas. $(\mathrm{dB})$

(b)

Figure 11: (a) Simulation of access and backhaul antennas system for configuration $1\left(\omega=180^{\circ}\right)$. (b) Simulation and experiment $S_{21}$ for $\omega=180^{\circ}$.

The experiment continues for $\omega=210^{\circ}$ up to $270^{\circ}$ with a step of $10^{\circ}$.

In configuration 2, the coupling effect is weaker compared to configuration 1 as it produces $S_{21}$ that varies from $-48 \mathrm{~dB}$ to $-68 \mathrm{~dB}$.

\section{Results}

In the tables that follow, the maximum value of experimental $S_{21}$ is denoted in the frequency range of $3.4 \mathrm{GHz}$ to $3.6 \mathrm{GHz}$, for each value of angle $\omega$.

In Table 2, the maximum values of $S_{21}$ in terms of angle $\omega$ for the configuration 1 are denoted. The frequency range of interest is 3.2 to $3.8 \mathrm{GHz}$.

The maximum value of $S_{21}$ as a function of the angle $\omega$ is depicted in Figure 19.

Table 3 follows together with the corresponded $S_{21}$ diagram. In Table 3, the maximum values of $S_{21}$ in terms of angle $\omega$ for the configuration 2 are denoted. The frequency range of interest is 3.2 to $3.8 \mathrm{GHz}$.

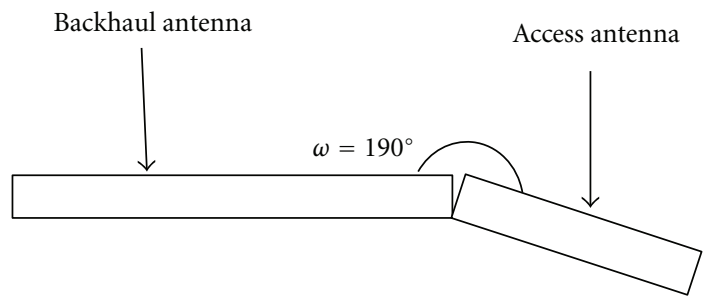

(a)

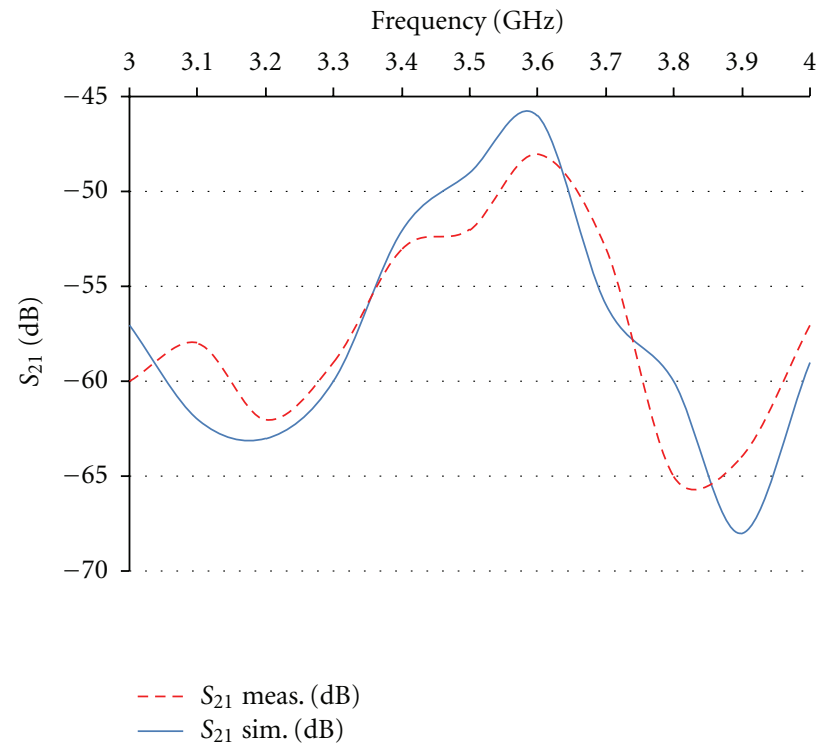

(b)

Figure 12: (a) Configuration for $\omega=190^{\circ}$. (b) $S_{21}$ for $\omega=190^{\circ}$.

TABLE 2: $S_{21}$ variation for configuration 1.

\begin{tabular}{ccc}
\hline Configuration 1 & $\omega$ (degrees) & $S_{21} \max (\mathrm{dB})$ \\
\hline 180 & -47.67 \\
190 & -46.84 \\
200 & -49.15 \\
210 & -50.46 \\
220 & -50.3 \\
230 & -50.56 \\
240 & -50.83 \\
250 & -54.94 \\
260 & -54.92 \\
270 & -53.94 \\
\hline
\end{tabular}

The maximum value of $S_{21}$ as a function of the angle $\omega$ is depicted in Figure 20.

Both configurations 1 and 2 provide a low level of coupling $\left(S_{21}<-40 \mathrm{~dB}\right)$. Coupling appears to decrease nonlinearly while $\omega$ increases. Configuration 2 is more acceptable because $S_{21}$ takes values lower than $-50 \mathrm{~dB}$ for all angles of $\omega$. The simulated coupling results provide some confidence that the levels will remain low between the angles at which measurements were performed.

A comparison in terms of coupling between the proposed antennas and the commercial ones presented in Table 1 


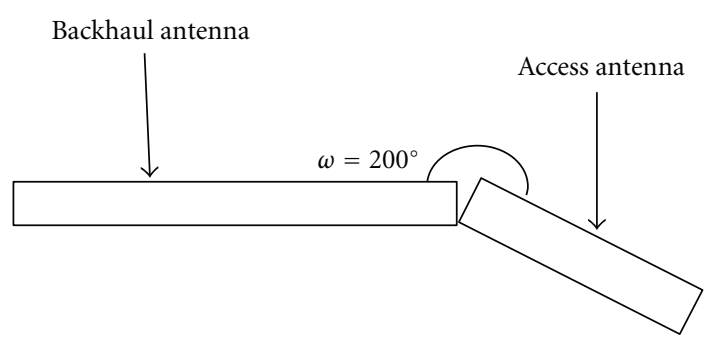

(a)

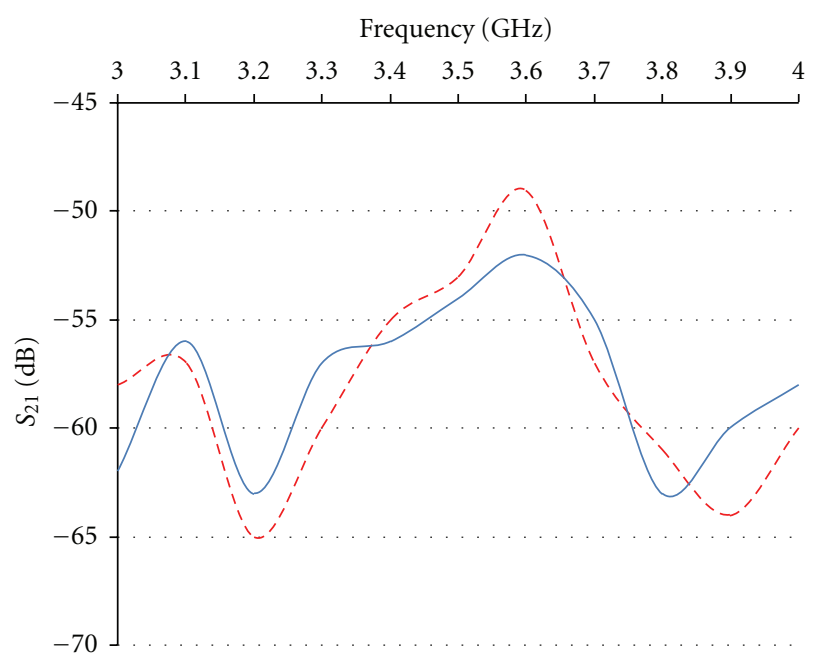

$--S_{21}$ meas. $(\mathrm{dB})$

$-S_{21} \operatorname{sim} .(\mathrm{dB})$

(b)

Figure 13: (a) Configuration for $\omega=200^{\circ}$. (b) $S_{21}$ for $\omega=200^{\circ}$.

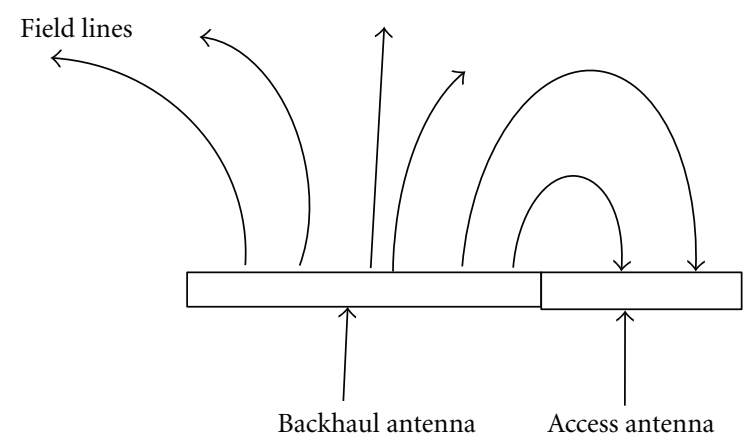

FIgURE 14: Field lines that cause coupling effect.

has also been performed. Both commercial and proposed antennas have been measured in terms of coupling for $\omega=$ $270^{\circ}$. The Relay set up including the suggested access and backhaul antenna can be seen in Figure 21.

Figure 22 shows coupling variations for commercial antennas and the proposed ones for configurations 1 and 2 at $\omega=270^{\circ}$.

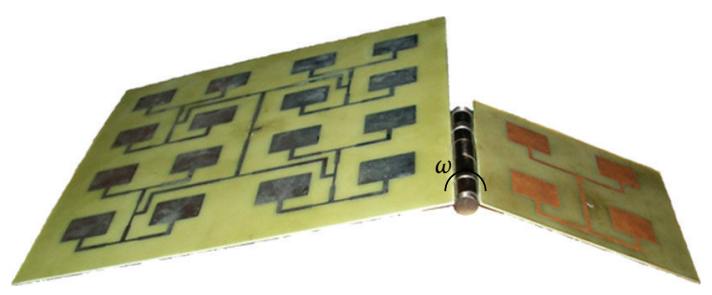

Figure 15: The investigated setup.

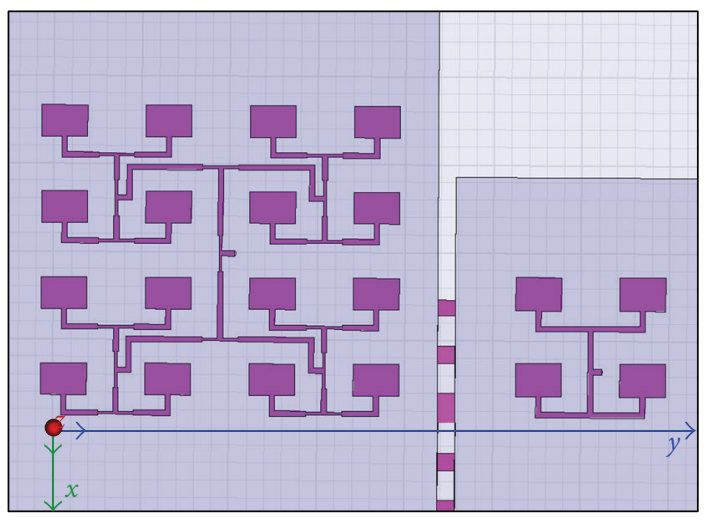

(a)

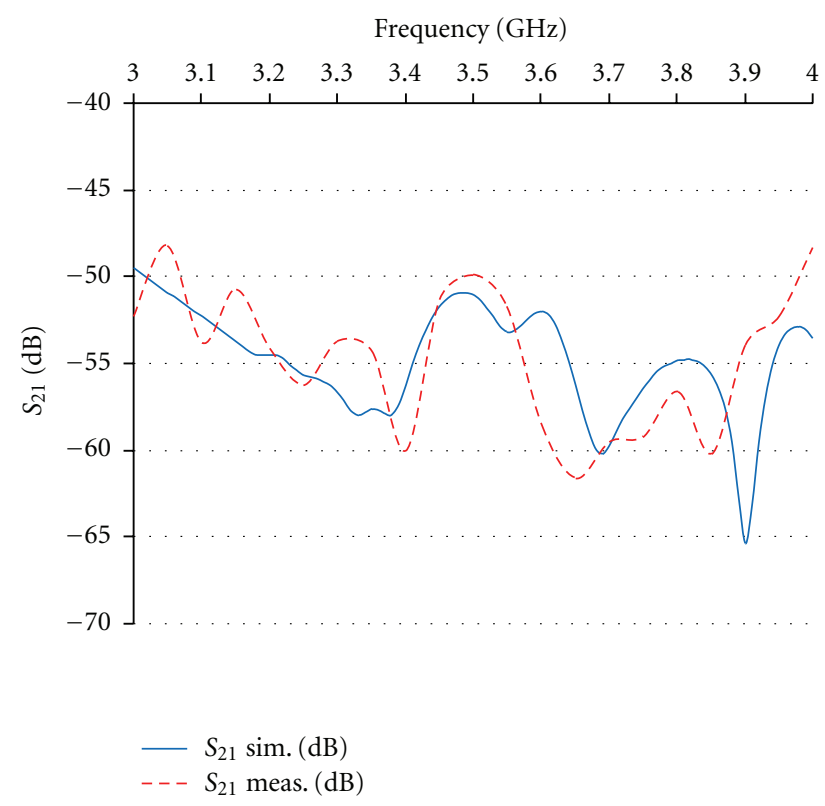

(b)

FIGURE 16: (a) Simulation of access and backhaul antennas for configuration $2\left(\omega=180^{\circ}\right)$. (b)Simulation and experiment $S_{21}$ for $\omega=$ $180^{\circ}$.

It is clear that both proposed configurations give lower values of $S_{21}$ compared to the commercial antennas proving the efficiency and competence of the suggested setup.

\section{Conclusions}

This paper describes the design, simulation, and testing of two microstrip antennas (access and backhaul). Antenna 


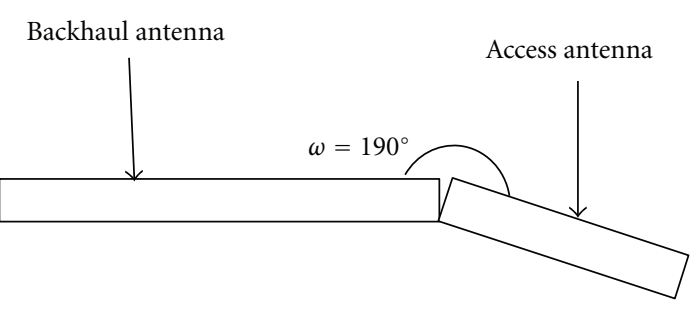

(a)

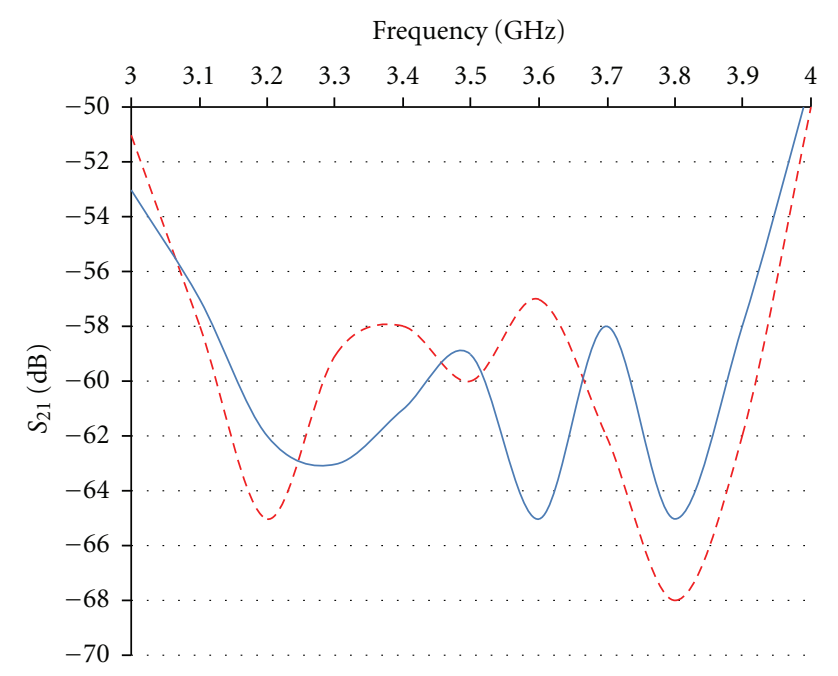

- - $S_{21}$ meas. $(\mathrm{dB})$

$-S_{21} \operatorname{sim} .(\mathrm{dB})$

(b)

Figure 17: (a) Configuration for $\omega=190^{\circ}$. (b) $S_{21}$ for $\omega=190^{\circ}$.

TABLE 3: $S_{21}$ variation for configuration 2.

\begin{tabular}{ccc}
\hline Configuration 2 & $\omega$ (degrees) & $S_{21} \max (\mathrm{dB})$ \\
\hline 180 & -55.56 \\
190 & -54.7 \\
200 & -57.34 \\
210 & -61.01 \\
220 & -60.26 \\
230 & -58.36 \\
240 & -59.1 \\
250 & -63.02 \\
260 & -65.35 \\
270 & -60.68 \\
\hline
\end{tabular}

characteristics in terms of gain, bandwidth, and beamwidth (HPBW) in xz and yz plane are approximately $8 \mathrm{dBi}, 32 \mathrm{MHz}$, $51^{\circ}$, and $36^{\circ}$ for the access antenna and $11.4 \mathrm{dBi}, 84 \mathrm{MHz}$, $25.5^{\circ}$, and $18^{\circ}$ for the backhaul antenna. $S_{11}$ parameters and radiation pattern in $\mathrm{xz}$ and $\mathrm{yz}$ plane level for simulated and fabricated antennas were presented. The comparison between measured and simulated results shows good agreement. Access and backhaul antennas were then alongside or above one another, and their interaction is investigated.

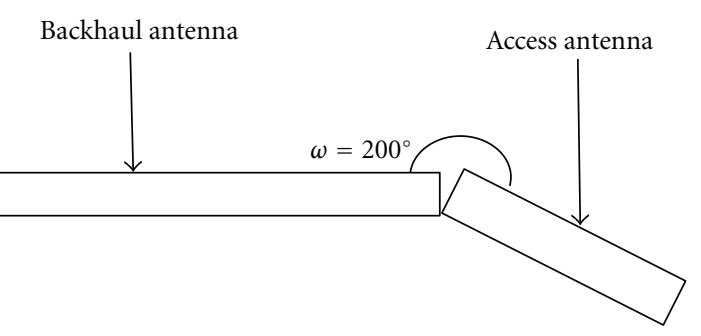

(a)

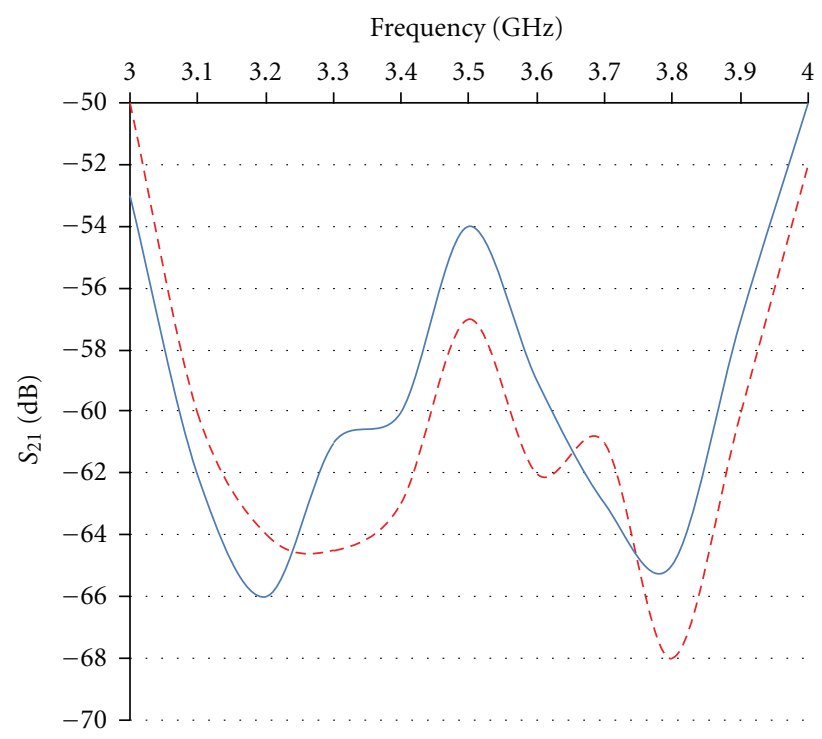

- - $S_{21}$ meas. $(\mathrm{dB})$

$-S_{21} \operatorname{sim} .(\mathrm{dB})$

(b)

Figure 18: (a) Configuration for $\omega=200^{\circ}$. (b) $S_{21}$ for $\omega=200^{\circ}$.

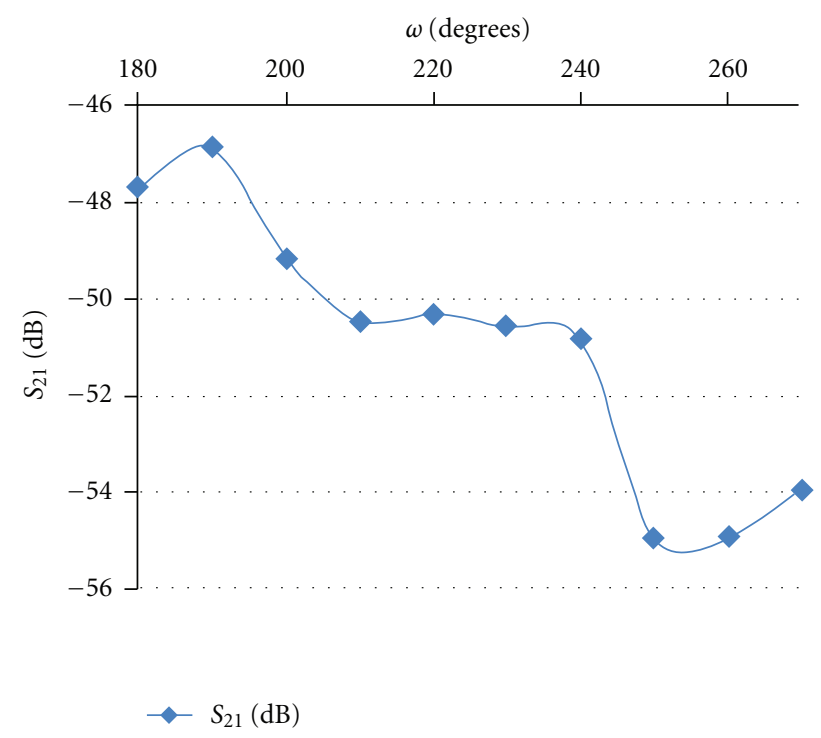

FIGURE 19: $S_{21}$ as a function of angle $\omega$ for configuration 1 . 


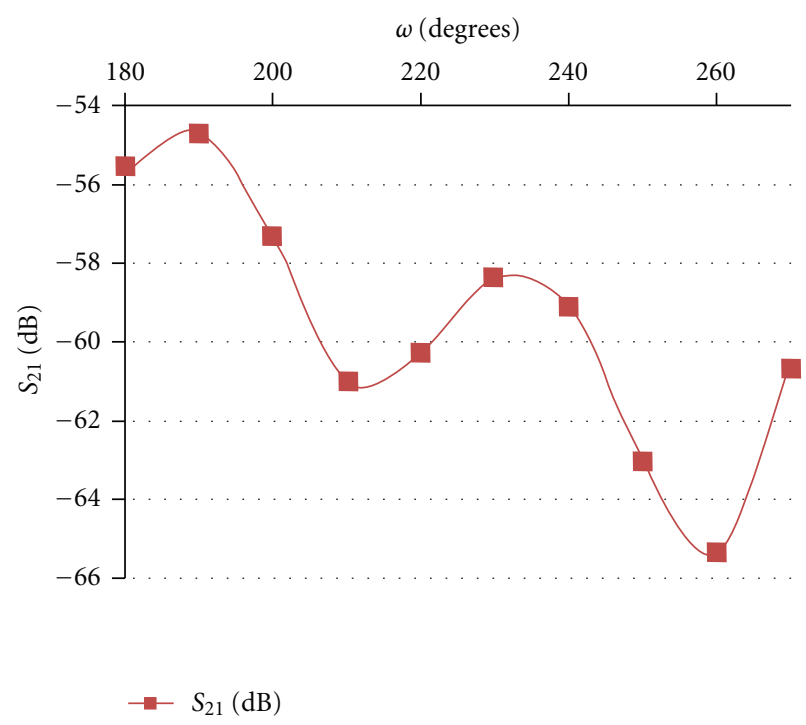

FIgURe 20: $S_{21}$ as a function of angle $\omega$ for configuration 2.

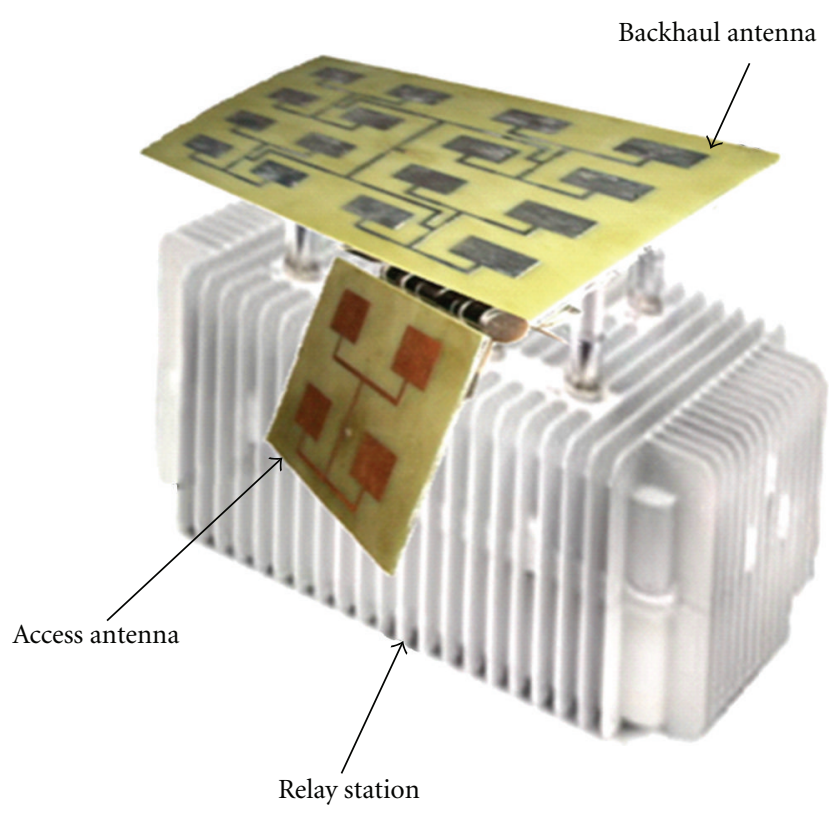

FIGURE 21: Relay station with the proposed antennas.

Two configurations are presented for which measured and simulated $S_{21}$ are given. Coupling $\left(S_{21}\right)$ is investigated against the angle between the antenna planes for the two configurations. Maximum values of $S_{21}$ against $\omega$ were presented for the frequency range of 3.4 to $3.6 \mathrm{GHz}$ in which the antennas operate. Coupling is typically below $-40 \mathrm{~dB}$. Diagrams of $S_{21}$ against $\omega$ show that coupling increases with increasing angle. Measurements and simulations show that the presented antennas could be used in both configurations under a relaybased network as they present an acceptably low level of interaction for all values of $\omega$. The comparison between the proposed patch antennas and the commercial ones prove that the suggested antennas provide $10 \mathrm{~dB}$ lower coupling providing low interaction and high isolation.

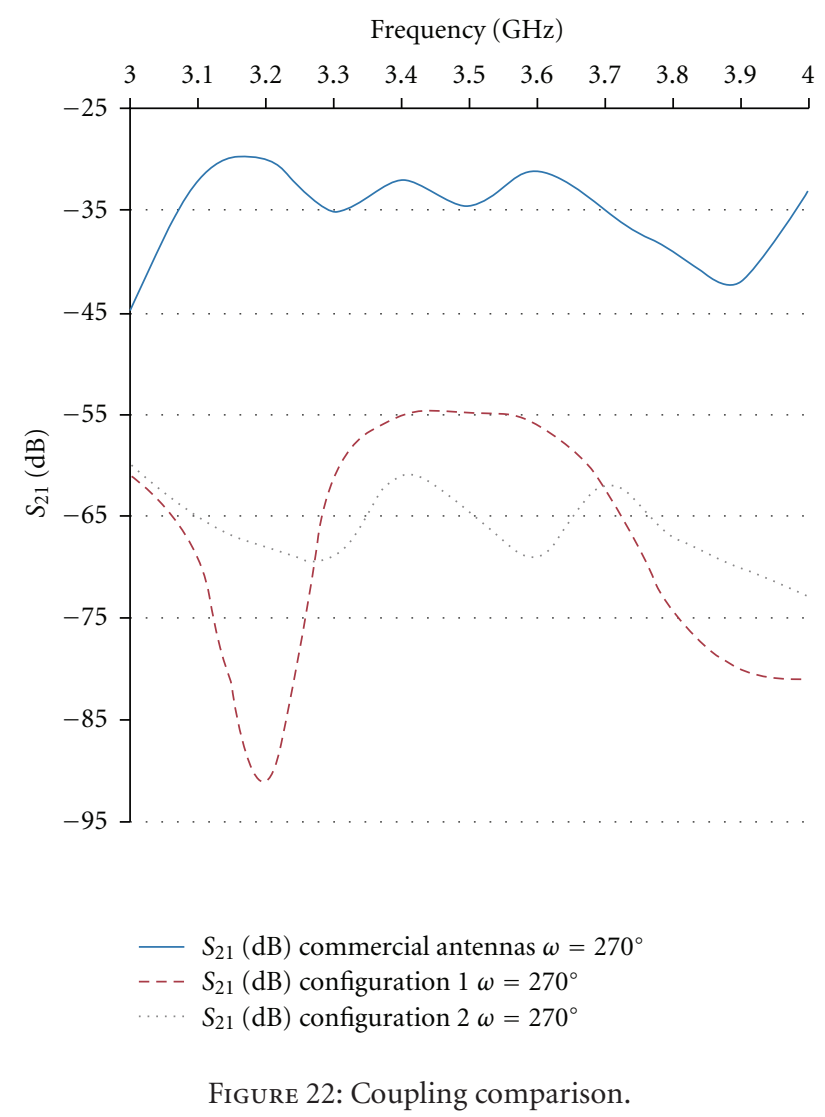

\section{Acknowledgments}

The present work has been performed in the scope of REWIND ("RElay based WIreless Network and StandarD”) European Research Project and has been supported by the Commission of the European Communities, Information Society and Media Directorate-General (FP7, ICT-The Network of the Future, Grant Agreement no. 216751).

\section{References}

[1] I. Georgas, I. Petropoulos, K. Voudouris et al., "Relay vs repeater architectures in WiMAX," in Proceedings of the 6th Internatiohal ICST Conference on Mobile Multimedia Communications (MOBEMEDIA '10), pp. 6-8, Lisbon, Portugal, September 2010.

[2] H. F. AbuTarboush, H. S. Al-Raweshidy, and R. Nilavalan, "Triple band double U-slots patch antenna for WiMAX mobile applications," in Proceedings of the 14th Asia-Pacific Conference on Communications (APCC '08), pp. 1-3, Akihabara, Japan, October 2008.

[3] B. Tlili, "Design of double C-slot microstrip patch antenna for WiMax application," in Proceedings of the IEEE International Symposium on Antennas and Propagation Society (APSURSI '10), pp. 1-4, Toronto, Canada, July 2010.

[4] K. L. Wong and H. C. Tung, "An inverted U-shaped patch antenna for compact operation," IEEE Transactions on Antennas and Propagation, vol. 51, no. 7, pp. 1647-1648, 2003.

[5] H. F. AbuTarboush, R. Nilavalan, H. S. Al-Raweshidy, and D. Budimir, "Design of planar inverted-F antennas (PIFA) for 
multiband wireless applications," in Proceedings of the International Conference on Electromagnetics in Advanced Applications (ICEAA '09), pp. 78-81, Torino, Italy, September 2009.

[6] S. Wang, L. Guo, X. Chen, C. G. Parini, and J. McCormick, "Analysis of mutual coupling in broadband arrays," in Proceedings of the IEEE International Symposium on Antennas and Propagation Society (AP-S '08), San Diego, Calif, USA, July 2008.

[7] H. M. Hizan and A. H. Awang, "Investigation of mutual coupling effect between five-element arrays of half cylindrical DRAs," in Proceedings of the Asian Conference on Sensors and the International Conference on new Techniques in Pharmaceutical and Biomedical Research, pp. 233-238, September 2005.

[8] Q. Zhou, Z. Y. Lei, P. Wang, Y. J. Xie, M. Xiang, and M. $\mathrm{He}$, "An accurate mutual coupling calculation for microstrip antennas for impedance mismatching," in Proceedings of the 7th International Symposium on Antennas, Propagation \& EM Theory (ISAPE'06), pp. 1-4, October 2006.

[9] M. Wang and Z. Shen, "Nulling of antenna arrays including the mutual coupling effect," in Proceedings of the IEEE 67th Vehicular Technology Conference (VTC'08), pp. 247-251, May 2008.

[10] L. Minz and R. Garg, "Reduction of mutual coupling between closely spaced PIFAs," Electronics Letters, vol. 46, no. 6, pp. 392-394, 2010.

[11] E. Rajo-Iglesias, O. Quevedo-Teruel, and L. Inclan-Sanchez, "Mutual coupling reduction in patch antenna arrays by using a planar EBG structure and a multilayer dielectric substrate," IEEE Transactions on Antennas and Propagation, vol. 56, no. 6, pp. 1648-1655, 2008.

[12] F. Caminita, S. Costanzo, G. Di Massa et al., "Reduction of patch antenna coupling by using a compact EBG formed by shorted strips with interlocked branch-stubs," IEEE Antennas and Wireless Propagation Letters, vol. 8, pp. 811-814, 2009.

[13] G. Kumar and K. P. Ray, Broadband Microstrip Antennas, Artech House, 2003.

[14] M. P. Abegaonkar, V. K. Aditya, A. Basu, and S. K. Koul, "Parametric study of a parasitically-fed broadband monopole patch antenna," in Proceedings of the 1st International Conference on Industrial and Information Systems (ICIIS '06), pp. 450-453, Peradeniya, Sri Lanka, August 2006.

[15] R. P. Jedlicka, M. T. Poe, and K. R. Carver, "Measured mutual coupling between microstrip antennas," IEEE Transactions on Antennas and Propagation, vol. 29, no. 1, pp. 147-149, 1981. 

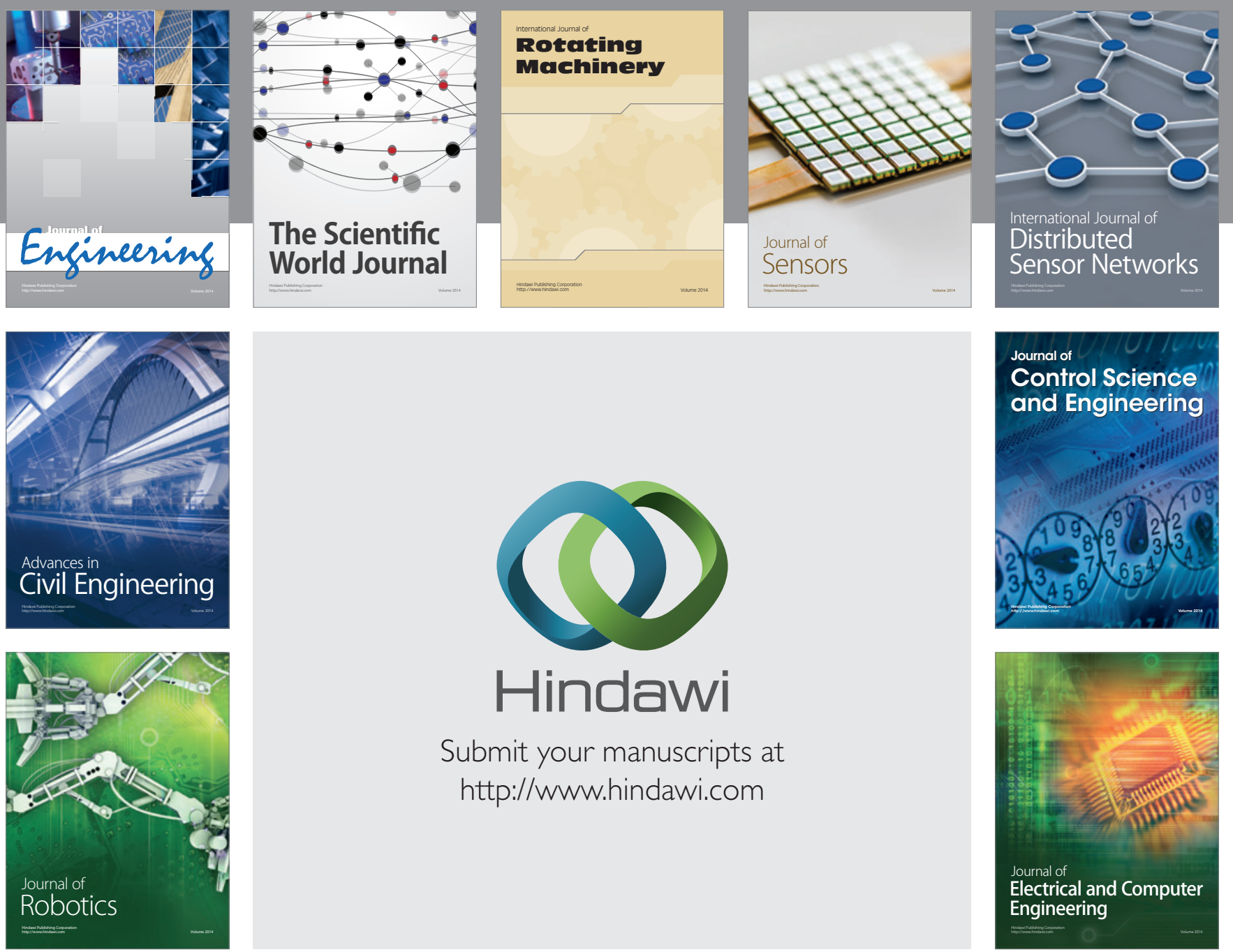

Submit your manuscripts at

http://www.hindawi.com
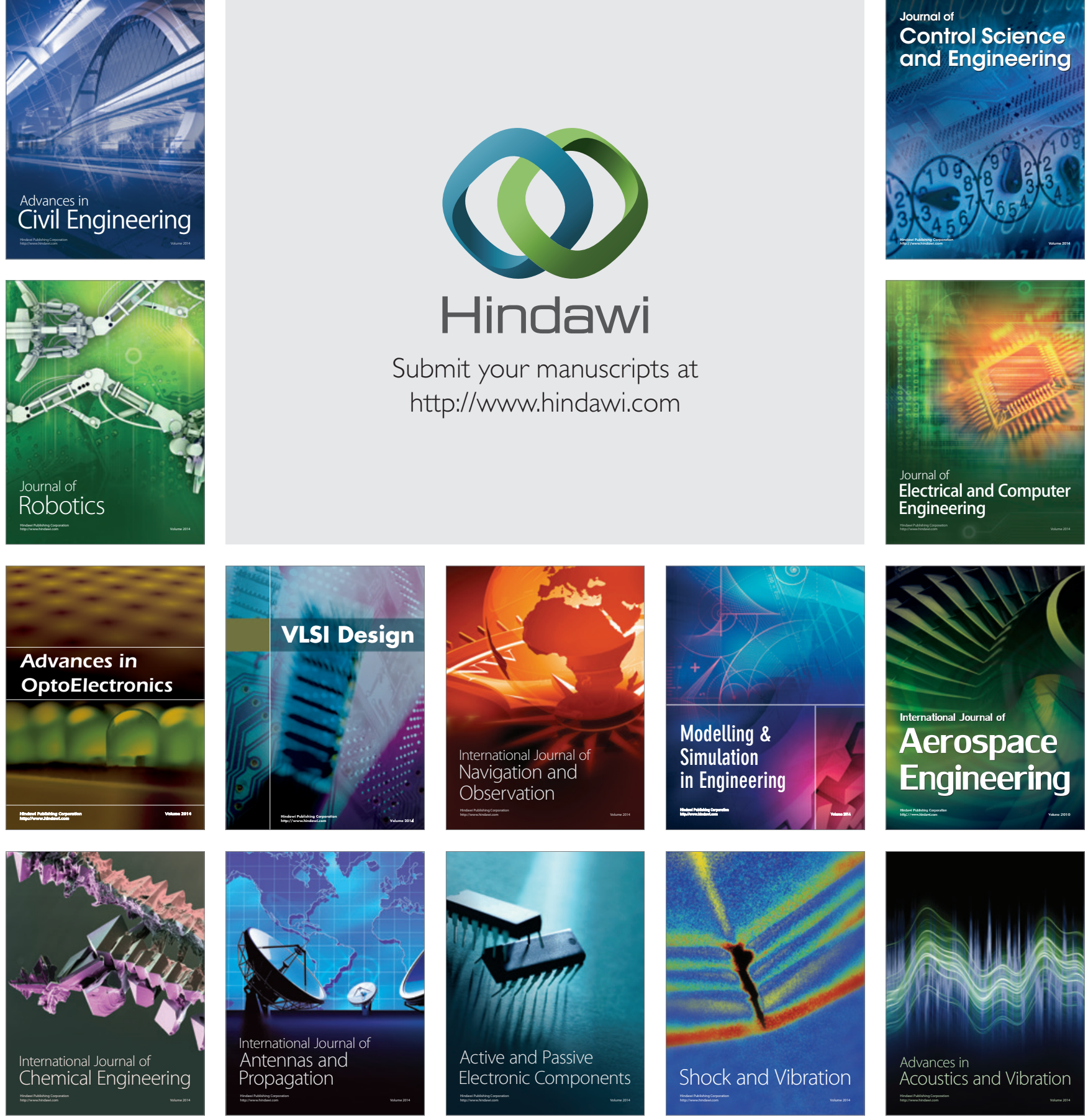